\title{
Analisis Kebutuhan Pengembangan Bahan Ajar Elektronik Mata Kuliah Desain dan Strategi Pembelajaran di IKIP Budi Utomo
}

\author{
Tri Asih Wahyu Hartati ${ }^{1}$, Luthfie Lufthansa ${ }^{2}$, Eva Nurul Malahayati ${ }^{3}$ \\ triasihibu@gmail.com ${ }^{1}$, dabluthfie@gmail.com² ${ }^{2}$, malahayatieva488@gmail.com³ \\ Pendidikan Biologi1,2, Pendidikan Jasmani Kesehatan dan Rekreasi² \\ IKIP Budi Utomo Malang ${ }^{1,2}$, Universitas Islam Balitar ${ }^{3}$
}

\begin{abstract}
Teaching materials are one of the factors that can affect the smoothness of the learning process and student learning outcomes. Design and Learning Strategies courses are compulsory subjects taught at the $\mathrm{S} 1$ level of the Health and Recreation Physical Education Study Program at IKIP Budi Utomo. Teaching materials for Design and Learning Strategies courses that are currently used are limited to printed teaching materials which contain material descriptions. The purpose of this study was to determine the needs of students in learning Design and Learning Strategy Subjects, especially in providing learning resources at IKIP Budi Utomo. This research method is descriptive quantitative. The research subjects were students of the 2018 IKIP Budi Utomo Recreation and Physical Education Study Program. The sample was randomly selected. They are collecting data through interviews with Subject Management Lecturers and student questionnaires. The results of the interviews show that the teaching materials used so far are still limited to printed teaching materials which contain descriptions of design materials and learning strategies in general, there are no specific examples of Physical Education learning designs and also important concepts of Physical Education learning. The results of the student need questionnaire analysis show that: 1) the teaching materials needed by students are in the form of electronic teaching materials (e-books), 2) the material in the teaching materials is material related to the specifications of the field of science, namely physical education learning.
\end{abstract}

Keywords: needs analysis, electronic teaching materials, learning design and strategies

Abstrak
Bahan ajar menjadi salah satu faktor yang dapat berpengaruh terhadap
kelancaran proses pembelajaran dan hasil belajar mahasiswa (Ardiansyah,
Corebima, \& Rohman, 2016). Mata kuliah Desain dan Strategi Pembelajaran
merupakan Mata kuliah wajib yang diajarkan pada jenjang S1 Program Studi
Pendidikan Jasmani kesehatan dan Rekreasi di IKIP Budi Utomo. Bahan ajar
Mata kuliah Desain dan Strategi Pembelajaran yang digunakan saat ini terbatas
pada bahan ajar cetak yang berisi uraian materi.Tujuan penelitian ini adalah
untuk mengetahui kebutuhan mahasiswa dalam pembelajaran Mata kuliah
Desain dan Strategi Pembelajaran terutama dalam penyediaan sumber belajar di
IKIP Budi Utomo. Metode penelitian ini adalah deskriptif kuantitatif. Subjek
penelitian adalah mahasiswa Program Studi Pendidikan Jasmani Kesehatan dan
Rekreasi IKIP Budi Utomo Angkatan 2018. Sampel penelitian menggunakan
random sampling. Pengumpulan data melalui wawancara dengan Dosen
Pengampu Mata kuliah dan angket mahasiswa. Hasil wawancara menunjukkan
bahwa bahan ajar yang digunakan selama ini masih terbatas pada bahan ajar
cetak yang berisi uraian materi desain dan strategi pembelajaran secara umum,
belum ada contoh spesifik desain pembelajaran Pendidikan Jasmani dan juga


konsep penting pembelajaran penjas. Hasil analisis angket kebutuhan mahasiswa menunjukkan bahwa: 1) bahan ajar yang diperlukan mahasiswa berupa bahan ajar elektronik (e-book), 2) materi di dalam bahan ajar merupakan materi yang terkait dengan spesifikasi bidang ilmu yaitu pembelajaran pendidikan jasmani.

Kata Kunci: analisis kebutuhan, bahan ajar elektronik, desain dan strategi pembelajaran

\section{PENDAHULUAN}

Bahan ajar merupakan komponen isi pesan dalam kurikulum yang harus diinformasikan pada mahasiswa dengan bentuk pesan yang beraneka ragam seperti fakta, konsep dan prosedur (Prastowo, 2012). Bagi Dosen/ Pendidik ketersediaan bahan ajar memegang peranan penting dalam proses pembelajaran karena dengan penggunaan bahan ajar yang tepat dapat meningkatkan efisiensi waktu mengajar serta mengubah peran seorang Dosen/ Pendidik dari sumber informasi menjadi fasilitator (Irawati \& Saifuddin, 2018). Bahan ajar menjadi salah satu komponen penting pula bagi mahasiswa karena dapat membantu mahasiswa memahami materi perkuliahan secara mandiri dan mengukur pencapaian kompetensi mereka. Menurut (Prastowo, 2012) bahan ajar dapat dikelompokkan menjadi bahan ajar cetak, bahan ajar dengar dan bahan ajar pandang dengar. Namun sesuai perkembangan zaman bahan ajar tidak hanya berupa buku (bahan ajar cetak) namun juga dapat diambil dari internet yang berupa artikel jurnal maupun buku elektronik/ e-book (Ardiansyah et al., 2016).

Mata kuliah Desain dan Strategi Pembelajaran merupakan mata kuliah yang wajib ditempuh oleh mahasiswa jenjang S1 Program Studi Pendidikan Jasmani Kesehatan dan Rekreasi di IKIP Budi Utomo Malang dengan bobot 3 sks. Mata kuliah Desain dan Strategi Pembelajaran disajikan di semester empat. Capaian Pembelajaran Mata kuliah Desain dan Strategi Pembelajaran adalah mahasiswa mampu merancang pembelajaran Pendidikan Jasmani yang selanjutnya disebut Penjas sesuai dengan karakteristik siswa dan ketersediaan sarana prasarana sekolah.

Berdasarkan hasil wawancara dengan Dosen Pengampu Mata kuliah Desain dan Strategi Pembelajaran diketahui bahwa kegiatan belajar mengajar yang berlangsung pada Mata kuliah Desain dan Strategi Pembelajaran di Program Studi Pendidikan Jasmani Kesehatan dan Rekreasi IKIP Budi Utomo selama ini masih tergantung kepada materi yang diberikan oleh Dosen. Dosen memberikan materi perkuliahan dalam bentuk power point presentation (ppt) dan handout. Belum ada bahan ajar yang sengaja dikembangkan oleh dosen terkait dengan karakteristik mata kuliah dan kebutuhan mahasiswa dalam pembelajaran Mata Kuliah Desain dan Strategi Pembelajaran. Dalam proses pembelajaran juga tampak kurangnya aktivitas belajar mahasiswa karena pembelajaran masih berpusat pada dosen (Teacher Centered Learning). Hal ini terlihat dari minimnya mahasiswa yang mengajukan pertanyaan, beberapa mahasiswa tidak memperhatikan penjelasan dosen, dan minimnya mahasiswa yang merespon pertanyaan dari dosen. 
Tujuan penelitian ini adalah untuk mengetahui bahan ajar yang perlu dikembangkan untuk Mata Kuliah Desain dan Strategi Pembelajaran di Program Studi Pendidikan Jasmani Kesehatan dan Rekreasi IKIP Budi Utomo yang sesuai dengan kebutuhan mahasiswa. Hasil dari penelitian ini menjadi rujukan dan dasar dalam pengembangan bahan ajar Mata Kuliah Desain dan Strategi Pembelajaran.

\section{METODE PENELITIAN}

Penelitian ini merupakan penelitian deskriptif kuantitatif yang dilakukan dengan metode survei pada bulan Maret-April 2020. Penelitian dilaksanakan di Program Studi Pendidikan Jasmani Kesehatan dan Rekreasi IKIP Budi Utomo Malang yang berada di Kampus A Jalan Simpang Arjuno 14B Malang. Populasi penelitian ini adalah seluruh mahasiswa aktif pada semester empat Program Studi Pendidikan Jasmani Kesehatan dan Rekreasi IKIP Budi Utomo tahun akademik 2019/2020 yang berjumlah 138 mahasiswa. Sampel penelitian menggunakan random sampling dengan subjek sebanyak 30 mahasiswa. Pengumpulan data dilakukan dengan metode wawancara, observasi dan penyebaran angket. Instrumen pengumpulan data menggunakan: (1) pedoman wawancara dengan dosen pengampu Mata Kuliah Desain dan Strategi Pembelajaran, (2) lembar observasi proses pembelajaran Mata Kuliah Desain dan Strategi Pembelajaran, dan (3) angket kebutuhan mahasiswa. Teknik analisis data untuk hasil penelitian menggunakan teknik analisis deskriptif kualitatif.

\section{HASIL DAN PEMBAHASAN}

Hasil observasi proses pembelajaran Mata Kuliah Desain dan Strategi Pembelajaran tersaji dalam Tabel 1. Sedangkan hasil analisis angket kebutuhan mahasiswa tersaji dalam Tabel 2 tentang Kendala yang dihadapi saat proses pembelajaran Mata Kuliah Desain dan Strategi Pembelajaran, Tabel 3 tentang Jenis sumber belajar mahasiswa dan Tabel 4 tentang Kebutuhan Bahan Ajar Mahasiswa.

Tabel 1. Hasil Observasi Proses Pembelajaran Mata kuliah Desain dan Strategi Pembelajaran

\begin{tabular}{llc}
\hline No & \multicolumn{2}{c}{ Hasil Observasi } \\
\hline 1 & Ada mahasiswa yang mengantuk, bermain HP, dan berbicara sendiri ketika Dosen menyampaikan \\
2 & materi perkuliahan & Dosen belum mengembangkan bahan ajar untuk perkuliahan Desain dan Strategi Pembelajaran \\
3 & Bahan ajar yang digunakan dosen berupa power point presentation (ppt) \\
4 & Dosen menjadi sumber referensi utama bagi mahasiswa & Jumlah (\%) \\
\hline \multicolumn{4}{c}{ Tabel 2. Kendala Mahasiswa dalam Perkuliahan Desain dan Strategi Pembelajaran } \\
\hline No & \multicolumn{1}{c}{ Jenis Kendala } & 3,3 \\
\hline 1 & Kurangnya alat prasarana pembelajaran & 20 \\
3 & Materi yang sulit dipahami & 76,7 \\
\hline
\end{tabular}

Tabel 3. Jenis Sumber Belajar Mahasiswa

\begin{tabular}{llc}
\hline No & \multicolumn{1}{c}{ Jenis Sumber Belajar } & Jumlah (\%) \\
\hline 1 & Artikel/ Jurnal IImiah & 13,3 \\
2 & Buku teks & 6,7 \\
3 & Internet & 80 \\
\hline
\end{tabular}


Tabel 4. Kebutuhan Jenis Bahan Ajar Mahasiswa

\begin{tabular}{llc}
\hline No & \multicolumn{1}{c}{$\begin{array}{c}\text { Jenis Bahan Ajar yang diperlukan } \\
\text { Mahasiswa }\end{array}$} & Jumlah (\%) \\
\hline 1 & Modul & 30 \\
2 & Buku ajar elektronik & 50 \\
3 & Handout & 3,3 \\
4 & Lembar Kerja Mahasiswa & 16,7 \\
\hline
\end{tabular}

Berdasarkan hasil observasi dan analisis angket kebutuhan didapatkan bahwa kendala terbesar yang dihadapi mahasiswa adalah kurangnya sumber belajar mahasiswa $(76,7 \%)$ dan materi yang sulit dipahami $(20 \%)$ sedangkan sumber belajar mahasiswa yang paling sering digunakan adalah $80 \%$ internet dan jenis bahan ajar yang diperlukan mahasiswa berupa buku ajar elektronik (50\%).

Mahasiswa menyatakan bahwa buku ajar elektronik adalah jenis bahan ajar yang diperlukan dan diinginkan untuk mempermudah mahasiswa dalam memahami materi Mata Kuliah Desain dan Strategi Pembelajaran. Menurut (Dwiyogo, 2013) salah satu keunggulan pengembangan bahan ajar elektronik adalah memudahkan pengembang memasukkan unsur suara/ audio dan gambar dinamis/ video sehingga dapat meningkatkan motivasi belajar mahasiswa. Bagian-bagian yang ada dalam bahan ajar elektronik akan memberikan kontribusi terhadap pengembangan keterampilan membaca, sikap dan motivasi mahasiswa dalam membaca teks digital (Muga, Suryono, \& Januarisca, 2017). Mahasiswa membutuhkan bahan ajar elektronik untuk saat ini karena bahan ajar elektronik memudahkan mahasiswa untuk mempelajari materi kapanpun dan dimanapun dengan akses yang cepat. Hal ini senada dengan (Jazuli, Azizah, \& Meita, 2018) yang menyatakan bahwa keberadaan bahan ajar elektronik menjadikan pendidik tidak harus hadir dalam kelas dan peserta didik dapat belajar secara mandiri sesuai minat dan gaya belajarnya. Saat ini $90 \%$ mahasiswa telah memiliki smartphone sehingga perangkat ini mendukung pengembangan bahan ajar elektronik.

Sebagian mahasiswa (20\%) menyatakan sulit untuk memahami materi pada Mata Kuliah Desain dan Strategi Pembelajaran sehingga dibutuhkan bahan ajar yang memuat materi dengan bahasa yang mudah untuk dipahami oleh mahasiswa. Nuha, Amin, \& Lestari (2016) menyatakan bahwa salah satu upaya untuk meningkatkan pemahaman mahasiswa adalah menyediakan buku ajar yang dapat memfasilitasi kegiatan belajar mahasiswa. Berkaitan dengan kegiatan belajar mahasiswa (Surahman \& Yeni, 2019) juga menyatakan bahwa proses belajar mahasiswa akan lebih efektif jika tersedia bahan ajar yang sesuai dengan materi yang disampaikan oleh pengajar. Hal ini menjadi salah satu dasar bagi peneliti untuk melanjutkan penelitian dengan mengembangkan/ menyediakan buku ajar yang sesuai dengan materi Mata Kuliah Desain dan Strategi Pembelajaran serta dirancang menggunakan bahasa yang lebih sederhana dan mudah dipahami oleh mahasiswa Program Studi Pendidikan Jasmani Kesehatan dan Rekreasi IKIP Budi Utomo. Selain itu pemberian contoh yang nyata dan sesuai dengan isu permasalahan yang dihadapi dalam kehidupan sehari-hari juga dapat meningkatkan pemahaman dan motivasi belajar mahasiswa. Hal ini diungkapkan oleh (Satriawan, 2016) yang menyatakan bahwa mahasiswa sangat tertarik untuk mempelajari materi karena contoh-contoh yang disajikan adalah isu nyata dalam kehidupan sehari-hari. 


\section{SIMPULAN}

Kesimpulan yang didapatkan dari hasil penelitian ini adalah diperlukannya bahan ajar elektronik pada pembelajaran Mata Kuliah Desain dan Strategi Pembelajaran yang menggunakan bahasa sederhana agar materi mudah dipahami dan disertai dengan contoh nyata yang sesuai dengan isu permasalahan yang dihadapi dalam kehidupan sehari-hari. Saran yang dapat diberikan adalah mengembangkan bahan ajar elektronik sesuai dengan kebutuhan mahasiswa dan compatible dengan perangkat/ smartphone yang dimiliki oleh mahasiswa agar mahasiswa dapat belajar kapanpun dan dimanapun.

Ucapan terima kasih disampaikan kepada: Direktorat Penelitian dan Pengabdian Kepada Masyarakat (DP2M) Kementrian Riset, Teknologi dan Pendidikan Tinggi yang telah membiayai penelitian ini pada skim Penelitian Dosen Pemula (PDP) Tahun 2020 dan Lembaga Penelitian dan Pengabdian kepada Masyarakat (LPPM) IKIP Budi Utomo yang telah memfasilitasi penelitian ini.

\section{DAFTAR RUJUKAN}

Ardiansyah, R., Corebima, A. D., \& Rohman, F. (2016). Analisis Kebutuhan Pengembangan Bahan Ajar Perubahan Materi Genetik pada Matakuliah Genetika di Universitas Negeri Malang. In Seminar Nasional Pendidikan dan Saintek 2016 (Vol. 2016, p. 1).

Dwiyogo, W. D. (2013). Media Pembelajaran. Malang: universitas negeri malang.

Irawati, H., \& Saifuddin, M. F. (2018). Analisis Kebutuhan Pengembangan Bahan Ajar Mata Kuliah Pengantar Profesi Guru Biologi Di Pendidikan Biologi Universitas Ahmad Dahlan Yogyakarta. Bio - Pedagogi: Jurnal Pembelajaran Biologi, 7(96-99), 96-99. Retrieved from https://jurnal.uns.ac.id/pdg/article/view/27636

Jazuli, M., Azizah, L. F., \& Meita, N. M. (2018). Pengembangan Bahan Ajar Elektronik Berbasis Android Sebagai Media Interaktif. LENSA (Lentera Sains): Jurnal Pendidikan IPA, 7(2), 47-65. https://doi.org/10.24929/lensa.v7i2.22

Muga, W., Suryono, B., \& Januarisca, E. L. (2017). PENGEMBANGAN BAHAN AJAR ELEKTRONIK BERBASIS MODEL PROBLEM BASED LEARNING DENGAN MENGGUNAKAN MODEL DICK AND CAREY. Journal of Education Technology, 1(4), 260-264.

Nuha, U., Amin, M., \& Lestari, U. (2016). Pengembangan Buku Ajar Berbasis Berbasis Penelitian Evolusi dan Filogenetik Molekuler untuk Matakuliah Evolusi di Universitas Jember. Jurnal Pendidikan: Teori, Penelitian, Dan Pengembangan, 1(9), 17911796.

Prastowo, A. (2012). Panduan Kreatif Membuat Bahan Ajar Inovatif. Yogyakarta: Diva Press.

Satriawan, M. (2016). Pengembangan Bahan Ajar Fisika Berbasis Kontekstual dengan Mengintegrasikan Kearifan Lokal untuk, 6(1).

Surahman, F., \& Yeni, H. O. (2019). Pengembangan Buku Ajar Mata Kuliah Renang Bagi Mahasiswa Pendidikan Jasmani Kesehatan dan Rekreasi. Journal Sport Area, 4(1), 218-229. https://doi.org/10.25299/sportarea.2019.vol4(1).2413 